J. Dairy Sci. 95:4683-4698

http://dx.doi.org/10.3168/jds.2011-5214

(C) American Dairy Science Association ${ }^{\circledR}, 2012$.

\title{
A simple formulation and solution to the replacement problem: A practical tool to assess the economic cow value, the value of a new pregnancy, and the cost of a pregnancy loss
}

V. E. Cabrera ${ }^{1}$

Department of Dairy Science, University of Wisconsin, Madison 53706

\begin{abstract}
This study contributes to the research literature by providing a new formulation for the cow replacement problem, and it also contributes to the Extension deliverables by providing a user-friendly decision support system tool that would more likely be adopted and applied for practical decision making. The cow value, its related values of a new pregnancy and a pregnancy loss, and their associated replacement policies determine profitability in dairy farming. One objective of this study was to present a simple, interactive, dynamic, and robust formulation of the cow value and the replacement problem, including expectancy of the future production of the cow and the genetic gain of the replacement. The proven hypothesis of this study was that all the above requirements could be achieved by using a Markov chain algorithm. The Markov chain model allowed (1) calculation of a forward expected value of a studied cow and its replacement; (2) use of a single model (the Markov chain) to calculate both the replacement policies and the herd statistics; (3) use of a predefined, preestablished farm reproductive replacement policy; (4) inclusion of a farmer's assessment of the expected future performance of a cow; (5) inclusion of a farmer's assessment of genetic gain with a replacement; and (6) use of a simple spreadsheet or an online system to implement the decision support system. Results clearly demonstrated that the decision policies found with the Markov chain model were consistent with more complex dynamic programming models. The final user-friendly decision support tool is available at http://dairymgt.info/ $\rightarrow$ Tools $\rightarrow$ The Economic Value of a Dairy Cow. This tool calculates the cow value instantaneously and is highly interactive, dynamic, and robust. When a Wisconsin dairy farm was studied using the model, the solution policy called for replacing nonpregnant cows 11 mo after calving or months in
\end{abstract}

Received November 30, 2011.

Accepted April 10, 2012.

${ }^{1}$ Corresponding author: vcabrera@wisc.edu milk (MIM) if in the first lactation and 9 MIM if in later lactations. The cow value for an average secondlactation cow was as follows: (1) when nonpregnant, (a) $\$ 897$ in MIM $=1$ and (b) $\$ 68$ in MIM = 8; (2) when the cow just became pregnant, ( a) $\$ 889$ for a pregnancy in $\mathrm{MIM}=3$ and (b) $\$ 298$ for a pregnancy in MIM = 8 ; and (3) the value of a pregnancy loss when a cow became pregnant in MIM $=5$ was (a) $\$ 221$ when the loss was in the first month of pregnancy and (b) $\$ 897$ when the loss was in the ninth month of pregnancy. The cow value indicated pregnant cows should be kept. The expected future production of a cow with respect to a similar average cow was an important determinant in the cow replacement decision. The expected production in the rest of the lactation was more important for nonpregnant cows, and the expected production in successive lactations was more important for pregnant cows. A $120 \%$ expected milk production for a cow with $\mathrm{MIM}=16$ and 6 mo pregnant in the present lactation or in successive lactations determined between 1.52 and 6.48 times the cow value, respectively, of an average production cow. The cow value decreased by $\$ 211$ for every 1 percentage point of expected genetic gain of the replacement. A break-even analysis of the cow value with respect to expected milk production of an average second-parity cow indicated that (1) nonpregnant cows in $\mathrm{MIM}=1$ and 8 could still remain in the herd if they produced at least 84 and $98 \%$ in the present lactation or if they produced at least 78 and $97 \%$ in future lactations, respectively; and (2) cows becoming pregnant in $\mathrm{MIM}=5$ would require at least $64 \%$ of milk production in the rest of the lactation or $93 \%$ in successive lactations to remain in the herd.

Key words: dynamic programming, Markov chain, herd simulation, replacement policy

\section{INTRODUCTION}

Estimating the value of future performance of a cow and future performance of a cow replacement as well as herd replacement decisions and policies in dairy farming are critical because they determine profitability 
(de Vries, 2006; Heikkilä et al., 2008; Cabrera, 2010). Dynamic programming (DP) based on Bellman's principle of optimality (Bellman, 1957) remains the state of the art to calculate the economic cow value (de Vries, 2006; Cabrera, 2010; Kalantari et al., 2010). However, a problem with DP formulation is the complexity of the model, which easily becomes very large and complicated (Demeter et al., 2011), with limited applicability to real-life problems, and is impractical for user-friendly decision support systems and for the day-to-day decisions of farmers (Smith et al., 1993; Groenendaal et al., 2004). For these reasons, Groenendaal et al. (2004) justified the use of the marginal net revenue method instead of DP to assess the cow value. They concluded that the marginal net review method accurately modeled the replacement problem and that, overall, their results were in agreement with previous studies using more complicated formulations of DP. They also indicated that because the model was contained in a spreadsheet, which is more familiar to dairy decision makers, it was better suited to support on-farm decisions. Nonetheless, they recognized that the marginal net revenue technique they used had important limitations, such as not including variation in expected cow performance and replacement genetic gain in the decisions.

The economic cow value is the difference between the discounted net return of a specific cow being evaluated and an average replacement cow (Eicker and Fetrow, 2003). If this value is positive, it is recommended to $k e e p$ the cow, and if it is negative, it is recommended to replace the cow (de Vries, 2004) because these decisions will improve the overall herd net return.

Standard DP is an iterative process of optimization that normally works backward from the future to the present. It calculates, in each iteration, the value of the cow if kept and the value of the cow if replaced. It uses the maximum of those values to connect from one iteration to the next, constructing an optimal replacement policy (Kristensen, 1987). Lactation state, pregnancy status, milk production, and other factors largely influence this pathway (de Vries, 2004, 2006). Results of a DP solution could show a matrix of cow values for all potential states of a cow. Some of these states would represent existing cows on a farm. However, thousands of those values would not represent an existing cow on a farm. Moreover, farmers know those cows that have a greater risk of being replaced at any specific point in time. Therefore, several calculations could be avoided or skipped to simplify the problem being solved. In addition, DP results are normally to be used with a second model, a Markov chain model, to calculate the resulting herd population, the overall herd net return, and other economic and herd structural parameters re- sponding to a DP optimal policy (de Vries, 2004, 2006; Kalantari et al., 2010).

The challenge, then, is to develop a simple algorithm to solve the replacement problem, address previous limitations of a simple problem formulation to include variations in cow performance and replacement genetic gain, and maintain an application that is highly user friendly and practical. This could be achieved by using solely the Markov chain model (St-Pierre and Jones, 2001; Cabrera et al., 2006,2008) to simulate the herd dynamics and then apply this value to the replacement problem by assessing the future profitability of the cow and the replacement. A limitation of this approach could be that, rather than an optimization, Markov chain is a simulation technique that requires a predefined original reproductive replacement policy. Nonetheless, this predefined reproductive replacement policy may be more aligned with the actual way commercial dairy farms operate. Over time, an interactive process with the model could be practiced to adjust this original policy by considering other farm constraints and goals. Normally, DP assumes an optimal policy for decisions in the future, and such a policy may not be achievable in real-life commercial dairy farm conditions.

Although DP results can give a full spectrum of cow value results for all potential cow states in a defined problem (Kalantari et al., 2010), the studies reported in the literature for DP did not present an opportunity to introduce external (out-of-the-model) parameters to interact with the model through recursive solutions. Specifically, it would be highly desirable to allow the decision maker to project the production performance of a specific cow being analyzed or estimate the expected genetic gain with a replacement. Allowing the decision maker to enter his or her knowledge and intuition goes beyond the full spectrum of model results and would provide a new dimension in the decision-making process. For instance, a farmer could use historical information on the animal, current health conditions, treatments required, and overall experience with the herd, combined with the modeling approach, to decide whether to keep or replace an animal.

The purpose of this study was then to (1) present a simple, interactive, dynamic, and robust formulation of the cow value and replacement problem based on a Markov chain model and develop a user-friendly decision support system based on the model formulation; and (2) describe the outcomes of the model within realistic scenarios.

\section{MATERIALS AND METHODS}

Based on the brief background above, the replacement problem was set to be solved by approximation 
by a simple algorithm alone based on a Markov chain model. The problem was further simplified because the value of a replacement remained constant for a defined level of genetic gain and defined herd parameters.

Under these premises, the replacement problem was solved by calculating the net present value (NPV) expected of a cow (NPV Cow) minus the net present value of a replacement (NPV Replacement) plus the cost of the replacement transaction, which included the cost of the replacement animal, the income received by the salvage value (of the replaced cow), and the calf born (to the replacement cow):

$$
\begin{gathered}
\text { cow value }=(\mathrm{NPV} \text { cow }-\mathrm{NPV} \text { replacement }) \\
+(\text { replacement cost }- \text { cow salvage value } \\
- \text { calf value })
\end{gathered}
$$

\section{The Markov Chain Cow Value Model}

A dairy herd was represented by a monthly Markov chain model as a matrix. Three states defined all potential cow states with respect to (1) months after calving or months in milk (MIM; 1 to 33), (2) months in pregnancy (MIP; 0 for nonpregnant, and 1 to 9 for pregnant), and (3) lactation (PAR; 1 to 10). The total number of states of the matrix was 2,320 after excluding impossible states (Cabrera et al., 2006).

The proportions of a cow $\left(\mathrm{COW}_{\mathrm{PAR}, \mathrm{MIM}, \mathrm{MIP}}\right)$ over time were simulated through Markov chains following previous models (St-Pierre and Jones, 2001; Cabrera et al., 2008; Bell et al., 2011). Vectors of transition probabilities with the dimension model represented the probabilities of a cow leaving the herd (CULL), becoming pregnant (PRG), and aborting (ABORT). Transition probabilities of a cow leaving the herd included nonreproductive culling, reproductive culling, and mortality. For simplicity in the formulation of the problem, they are all denoted with CULL.

The fractions of a cow in a state in the next month $\left(\mathrm{COW}_{\mathrm{MIM}+1, \mathrm{MIP}, \mathrm{PAR}}\right)$ were simulated following the equations below:

Proportions of a nonpregnant cow remaining in the herd and not becoming pregnant:

$$
\begin{gathered}
\left(\mathrm{COW}_{\mathrm{MIM}+1,0, \mathrm{PAR}}\right)=\left(\mathrm{COW}_{\mathrm{MIM}, 0, \mathrm{PAR}}\right) \\
\left(1-\mathrm{CULL}_{\mathrm{MIM}, 0, \mathrm{PAR}}\right)\left(1-\mathrm{PRG}_{\mathrm{MIM}, 0, \mathrm{PAR}}\right) ;
\end{gathered}
$$

Proportions of a nonpregnant cow remaining in the herd and becoming pregnant:

$$
\begin{gathered}
\left(\mathrm{COW}_{\mathrm{MIM}+1,1, \mathrm{PAR}}\right)=\left(\mathrm{COW}_{\mathrm{MIM}, 0, \mathrm{PAR}}\right) \\
\left(1-\mathrm{CULL}_{\mathrm{MIM}, 0, \mathrm{PAR}}\right)\left(1-\mathrm{PRG}_{\mathrm{MIM}, 0, \mathrm{PAR}}\right) ;
\end{gathered}
$$

Proportions of a pregnant cow remaining in the herd and not aborting:

$$
\begin{gathered}
\left(\mathrm{COW}_{\mathrm{MIM}+1, \mathrm{PRG}+1, \mathrm{PAR}}\right)=\left(\mathrm{COW}_{\mathrm{MIM}, \mathrm{MIP}, \mathrm{PAR}}\right) \\
\left(1-\mathrm{CULL}_{\mathrm{MIM}, \mathrm{MIP}, \mathrm{PAR}}\right)\left(1-\mathrm{ABORT}_{\mathrm{MIM}, \mathrm{MIP}, \mathrm{PAR}}\right)
\end{gathered}
$$

Proportions of a pregnant cow remaining in the herd and aborting:

$$
\begin{gathered}
\left(\mathrm{COW}_{\mathrm{MIM}+1,0, \mathrm{PAR}}\right)=\left(\mathrm{COW}_{\mathrm{MIM}, \mathrm{MIP}, \mathrm{PAR}}\right) \\
\left(1-\mathrm{CULL}_{\mathrm{MIM}, \mathrm{MIP}, \mathrm{PAR}}\right)\left(1-\mathrm{ABORT}_{\mathrm{MIM}, \mathrm{MIP}, \mathrm{PAR}}\right)
\end{gathered}
$$

Proportions of a cow calving and moving to a subsequent parity:

$$
\begin{aligned}
& \left(\mathrm{COW}_{1,0, \mathrm{PAR}+1}\right)= \\
& \sum_{\text {MIM }=11}^{33}\left(\mathrm{COW}_{\text {MIM }, 9, \mathrm{PAR}}\right)\left(1-\mathrm{CULL}_{\text {MIM }, 9, \mathrm{PAR}}\right)\left(1-\mathrm{ABORT}_{\text {MIM }, 9 \text { PAR }}\right),
\end{aligned}
$$

Proportions of a cow leaving the herd (CULL) for any reason (nonreproductive culling, reproductive culling, or mortality) were replaced with a first month in milk $(\mathrm{MIM}=1)$, nonpregnant $(\mathrm{MIP}=0)$, and first parity $(\mathrm{PAR}=1)$ replacement cow $\left(\mathrm{COW}_{1,0,1}\right.$; de Vries, 2004 ; Cabrera et al., 2006, 2008). Therefore,

$$
\begin{aligned}
& \left(\mathrm{COW}_{1,0,1}\right)= \\
& \sum_{\mathrm{MIM}=11}^{33} \sum_{\mathrm{MIP}=0}^{9} \sum_{\mathrm{PAR}=1}^{10}\left(\mathrm{COW}_{\mathrm{MIM}, \mathrm{MIP}, \mathrm{PAR}}\right)\left(\mathrm{CULL}_{\mathrm{MIM}, \mathrm{MIP}, \mathrm{PAR}}\right) .
\end{aligned}
$$

The cow being evaluated and its potential replacement differed only in their current state: the replacement was always a cow beginning the iterative process of the Markov chain as a cow in MIM $=1, \operatorname{MIP}=0$, and PAR $=1\left(\mathrm{COW}_{1,0,1}\right)$, whereas the cow being analyzed could be in any state defined in the model. The probabilistic life of a cow or a replacement was then represented from the time the cow was being analyzed to a point in the future when the cow and all its replacements had reached the Markov chain condition of steady state (Cabrera and Giordano, 2010). At the first iteration (same point in time, same month), the cow being analyzed and the replacement cow are in different states. Over the long term, at some time in the future, the probabilities of a cow in all states defined in the model no longer change from one iteration to the next. This is known as the Markov chain condition of steady state. The model reaches a steady state regardless of the current state of the cow or replacement in the first iteration (Hillier and Lieberman, 1986). Therefore, the 
proportions of a cow at steady state are the same for both the cow being analyzed and the replacement.

The model was solved through recursive iterations until the probability distribution of a cow across all states of the model reached a steady state. In each iteration, an aggregated discounted net return (incomes minus costs) of all the probabilities of the cow were es- timated. It was found empirically that steady state was consistently reached in less than 120 iterations. The model was then arbitrarily set to always run 150 iterations and ensure that the value comparison between the cow and the replacement was always consistent at steady state and at the same number of iterations for both the cow being analyzed and the replacement.

\section{Economic Module}

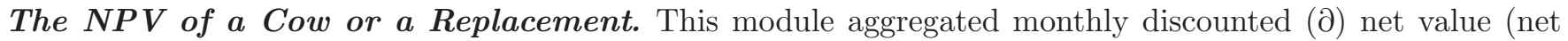
return) over the 150 iterations $(150 \mathrm{mo}, i)$ that resulted in the NPV cow (value of keeping the cow) or in the NPV replacement (value of replacing the cow). Economic factors used in this calculation were those incomes and costs that are most likely to change across the life of a cow: (1) milk income ( $M i)$, milk production according to the expected lactation curves multiplied by the milk price (pregnant cows had a milk depression factor related to gestation time, including a dry period with no milk production when close to parturition); $(2)$ feed cost $(F c)$, feed consumption according to $2 \%$ BW and $30 \%$ of $4 \%$ FCM production (VandeHaar et al., 1992) multiplied by the feed cost, which distinguished feed cost for lactating cows and feed cost for dry cows; (3) calf income (Ci), calf weighted average value; (4) nonreproductive culling cost $(N R C c)$, cost of a replacement animal (pregnant heifer ready to deliver that joins the herd as $\mathrm{PAR}=1, \mathrm{MIM}=1$, and $\mathrm{MIP}=0$ ) minus the salvage value of the culled animal minus the income of the calf coming with the replacement; $(5)$ mortality cost $(M c)$, cost of a replacement animal offset by the income of the calf coming with the replacement; (6) reproductive culling cost $(R C c)$, same cost as $N R C c$; and (7) reproductive costs $(R c)$, cost incurred on labor, hormones (if any), AI, and pregnancy diagnosis of the reproductive program.

Therefore,

$$
\begin{aligned}
& \text { NPV cow or NPV replacement }= \\
& \sum_{i=1}^{150} \partial\left[\sum_{\mathrm{PAR}=\text { par }}^{10} \sum_{\text {MIM }=\text { mim }}^{33} \sum_{\text {MIP }=\text { mip }}^{9}(m i-F c+C i-N R C c-M c-R C c-R c)_{M I M, M I P, P A R}(C O W)_{M I M, M I P, P A R}\right]_{i},
\end{aligned}
$$

where par, mim, and mip define the cow being analyzed and are any value within the defined dimensions of the model ( 1 to 10, 1 to 33 , and 0 to 9 , respectively) when calculating the NPV cow. These were always 1,1 , and 0 when calculating the NPV replacement.

The Value of a New Pregnancy. The value of a new pregnancy within this formulation was then defined as the difference in the cow value of a recently pregnant cow $(\mathrm{MIP}=1)$ and the cow value of a nonpregnant cow $(\mathrm{MIP}=0)$ at the same MIM and PAR:

$$
\begin{gathered}
\text { value of a new pregnancy }=\text { cow value } \text { MIM }, 1, \mathrm{PAR} \\
- \text { cow value } \mathrm{MIM}, 0, \mathrm{PAR} .
\end{gathered}
$$

The Cost of a Pregnancy Loss. The cost of a pregnancy loss was then defined as the difference in the cow value of a pregnant cow $(\mathrm{MIP} \geq 1)$ and the cow value of a nonpregnant cow $(\mathrm{MIP}=0)$ at the same MIM and PAR:

cost of a pregnancy loss $=$

cow value MIM,MIP $\geq 1$, PAR - cow value MIM,, PAR $_{\text {. }}$ 
Table 1. List of minimum variables required to calculate the cow value using the Markov chain model, and base values used in the model illustration

\begin{tabular}{|c|c|}
\hline Variable & Base value \\
\hline \multicolumn{2}{|l|}{ Cow variable evaluated } \\
\hline Current lactation & Cow specific ( 1 to 10$)$ \\
\hline Current month after calving or month in milk (MIM) & Cow specific ( 1 to 33 ) \\
\hline Current month in pregnancy & Cow specific ( 0 to 9$)$ \\
\hline Current milk production, ${ }^{1} \mathrm{~kg} / \mathrm{d}$ & Cow specific \\
\hline Expected milk production for rest of lactation, $\%$ & 100 \\
\hline Expected milk production in next lactations, \% & 100 \\
\hline \multicolumn{2}{|l|}{ Replacement cow variable } \\
\hline Genetic improvement, \% & 0 \\
\hline \multicolumn{2}{|l|}{ Herd variable } \\
\hline Herd turnover ratio, $\% / y r$ & 35 \\
\hline Rolling herd average, $\mathrm{kg} / \mathrm{cow}$ per year & 10,896 \\
\hline 21 -d pregnancy rate, $\%$ & 18 \\
\hline Reproduction cost, $\$ /$ cow per month & 20 \\
\hline Last MIM to breed a cow ${ }^{2}$ & 10 \\
\hline Milk threshold ${ }^{3} \mathrm{~kg} / \mathrm{cow}$ per day & 22.7 \\
\hline Pregnancy loss after $35 \mathrm{~d}$ pregnant, $\%$ & 22.6 \\
\hline Average cow BW, kg & 593 \\
\hline \multicolumn{2}{|l|}{ Economic variable } \\
\hline Replacement cost, $\$ /$ cow & 1,300 \\
\hline Salvage value, $\$ / \mathrm{kg}$ of live weight & 0.84 \\
\hline Calf value, $\$ /$ calf & 100 \\
\hline Milk price, $\$ / \mathrm{kg}$ & 0.35 \\
\hline Milk butterfat, $\%$ & 3.5 \\
\hline Feed cost for lactating cows, $\$ / \mathrm{kg}$ of $\mathrm{DM}$ of diet & 0.22 \\
\hline Feed cost for dry cows, $\$ / \mathrm{kg}$ of $\mathrm{DM}$ of diet & 0.18 \\
\hline Interest rate, $\% / \mathrm{yr}$ & 6 \\
\hline
\end{tabular}

\section{Data Required for Model Application}

For simplicity and to keep the model as a user-friendly decision support system with a minimum number of inputs (Table 1), some approximations were made, such as scaling transition probabilities corresponding to pregnancy, abortion, BW, and culling rates to respond to only a few user inputs. In general, every effort was made to keep the model simple to run from the standpoint of the data needed, to be easily and readily available to the users. It was then possible to run the model by requiring only the following inputs (defined in the next section): 6 cow variables (for the cow evaluated), 1 cow variable (for the replacement cow), 8 herd variables, and 8 economic variables. Although these variables were internally adjusted and scaled to match all the transition probabilities and states included, the model was prepared to customize any single more detailed parameter for analysis purposes. It was believed that this set of minimum variables would give relevant and useful results from a decision-making standpoint for the user-friendly application.

\section{Cow Variables}

$P A R, M I M$, and $M I P$. These variables locate the analyzed cow at the starting point (month or iteration $=1$ ) in the Markov chain model. Any adult cow in the herd can be described in terms of lactation, months after calving, and pregnancy status.

Current Milk Production ( $\mathrm{kg} / \mathrm{d})$, Expected Milk Production for the Rest of Lactation (\%), and Expected Milk Production in the Next Lactations (\%). The NPV cow could be calculated assuming the cow produces average milk production throughout its life or assuming a differential production. For the decision support system, first, user-entered, cow-specific milk production (corresponding to lactation, MIM, and MIP) is used as a referential figure. This amount is internally divided by the average milk production expected for an average cow in that state in the herd and expressed as a percentage. The user then knows the milk production of the analyzed cow in relation with the average herd cow at the specific MIM, MIP, and PAR. On the basis of such value and previous knowledge of cow performance, genetics, health problems, and other 
considerations, the farmer can enter an estimate of the production level (\%) of that cow related to the herd average cow for the rest of the current lactation. Further, the user can enter a similar assessment (\%) about the expectation of milk production that cow would have in relation to the herd average cow for successive lactations. Using $100 \%$ for both values assumes that the cow being evaluated would perform at the average level. These 2 milk production percentages are applied to the cow being analyzed and not to the cow's replacement.

\section{Replacement Variable: Genetic Improvement (\%)}

A replacement is normally assumed to have average genetic traits of the herd and average production lactation curves. Expected improved traits of a replacement can be summarized in improved milk production. The farmer then has the opportunity to enter a percentage value of additional milk to be expected with a replacement compared with the current average cow in the herd. This value applies to the replacement when calculating the NPV replacement.

\section{Herd Variables}

Herd Turnover Ratio (\%/yr). This is defined as one single value expressed as percentage per year that represents the total proportion of animals that left the herd over a 1-yr period. Based on this value, the model internally builds several monthly transition matrices of culling and mortality: nonreproductive culling for nonpregnant cows by lactation and MIM, mortality for nonpregnant cows by lactation and MIM, culling for pregnant cows by lactation and MIM, and mortality for pregnant cows by lactation and MIM. The aggregation of all these is represented in the formulation of the problem as CULL MIM,MIP,PAR. First, data from de Vries et al. (2010) were used to represent a specific turnover ratio (e.g., 35\%/yr) by lactation and MIM. These values are then split into nonreproductive culling and mortality, assuming that $10 \%$ of the turnover is mortality (AgSource Cooperative Services, Verona, WI). Then, $25 \%$ of culls and mortality of the nonpregnant cows were used for the pregnant group (de Vries et al., 2010). These procedures were calibrated to approximate the model-estimated turnover ratio to the one entered. Nonetheless, small differences between the 2 values would always occur because reproductive culling and herd population dynamics within the Markov chain structure interact dynamically with this herd turnover ratio.

Rolling Herd Average (kg/Cow per Year). A rolling herd average of $10,896 \mathrm{~kg} / \mathrm{cow}$ per year was used as a base figure (Table 1). Internally, data provided by
AgSource Cooperative Services that included 326,000 lactations during a 5-yr period (2003 to 2007) were used to fit lactation curves to the MilkBot model (Ehrlich, 2011) according to production levels and lactations $(1,2$, and $\geq 3)$. The user then selects a predetermined level between 8,172 and $13,620 \mathrm{~kg} /$ cow per year $(18,000$ and $30,000 \mathrm{lb} /$ cow per year) in $454-\mathrm{kg}$ increments. The model included a database of MilkBot parameters (scale, ramp, offset, and decay) that are used to project lactation curves $(1,2$, and $\geq 3)$ that represent a user-defined rolling herd average (Ehrlich, 2011). Following Cabrera and Giordano (2010), a factor of milk production depression of 5,10 , and $15 \%$ attributable to gestation was applied to cows in MIP $=5,6$, and 7 , respectively.

21-d Pregnancy Rate (\%) and Reproduction Cost (\$/Cow per Month). The 21-d pregnancy rate was used as the metric of reproductive efficiency. The model internally converts this value to a monthly pregnancy rate, and then it is used assuming a voluntary waiting period of $50 \mathrm{~d}$ postpartum. The variable reproduction cost could be estimated by the addition of labor, hormones (if any), artificial insemination, and pregnancy diagnosis, whether the farmer uses heat detection only, synchronization programs only, or a combination of both.

Last MIM to Breed and Milk Threshold to Cull for Reproductive Failure (kg/Cow per Day). These 2 parameters complete the reproductive program definition. The first variable, last MIM to breed, imposes a limit to when the farmer makes the last breeding service to a nonpregnant cow. The second variable, milk threshold for reproductive failure, defines the minimum level of milk production a cow could have to remain in the herd after the last MIM to breed. If the cow is producing more milk than the milk threshold after the last MIM to breed, then the cow remains in the herd, but no more reproductive services are performed on that cow (cow labeled as "do not breed"). When the milk produced by the cow falls below the milk threshold, the cow is removed from the herd as a reproductive cull animal.

Pregnancy Loss (\% After 35 d in Gestation). This expected abortion is distributed between $35 \mathrm{~d}$ and the end of gestation, scaling the abortion curve reported by de Vries (2006). This abortion risk repeats in different lactations.

Average Cow BW ( $\mathrm{kg} /$ Cow). An average of BW of $593 \mathrm{~kg}$ (504 kg for primiparous and $603 \mathrm{~kg}$ for multiparous) was used as the base figure (Table 1). The Korver function (Korver et al., 1985) fitted to the NRC (2001) BW function was used to determine the BW of the cow by PAR and MIM according to the user-input average $\mathrm{BW}$. The user is required to enter only one number to be representative of the herd. 


\section{Economic Variables}

The base values of variables used in the study (defined below) are presented in Table 1. Users of the decision support system should define farm-specific values.

Replacement Value (\$/Cow). The replacement value is the cost to buy a pregnant heifer ready to calve. The animal calves on the farm and joins the herd as $\mathrm{MIM}=1, \mathrm{MIP}=0, \mathrm{PAR}=1$.

Salvage Value $(\$ / \mathbf{k g}$ of Live Weight). The salvage value is the income received when selling an animal for meat purposes. This is also known as the cull value.

Calf Value (\$/Calf). The calf value is the income received when selling a newborn. This value represents a weighted average of the proportions of males and females born alive and their corresponding market prices.

Milk Price $(\boldsymbol{\$} / \mathbf{k g})$. The milk price is the average or long-term estimated farm price received for the kilograms of milk sold. This is used to calculate the herd milk income.

Milk Butterfat (\%). The milk butterfat is the average or long-term estimated fat content of the milk produced on the farm. This is used to calculate the FCM.

Feed Cost for Lactating Cows $(\$ / \mathbf{k g})$. The feed cost for lactating cows is the average or long-term estimated cost per kilogram of DM of diet provided to the lactating cows. This cost applies to all lactating cows in the herd.

Feed Cost for Dry Cows $(\$ / k g)$. Feed cost for dry cows is the average or long-term estimated price per kilogram of DM of diet provided to dry cows (pregnant and close to delivery). Following standard dairy farm practice, a 2-mo dry period (60 d) was assumed.

Interest Rate (\%/yr). The interest rate is the expected interest rate applied to the money invested. A good approximation to be used is the difference between the nominal interest rate paid for a bank loan minus the inflation rate.

\section{Model Illustration}

The model performance was demonstrated using data representative of a farm in Wisconsin (Table 1). As would be common to find in Wisconsin, the farm herd had a turnover ratio of $35 \% / \mathrm{yr}$, an average milk production of $10,896 \mathrm{~kg} / \mathrm{cow}$ per year, a 21 -d pregnancy rate of $18 \%$, a pregnancy loss of about $22.6 \%$, and an average cow BW of $593 \mathrm{~kg}$. The farm cut-off time to stop breeding was 300 DIM (10 mo), and the milk threshold to remove nonpregnant cows was 22.7 $\mathrm{kg}$. The farm incurred a cost of $\$ 20 /$ cow per month for reproductive matters, $\$ 1,300$ for a replacement animal, $\$ 0.22 / \mathrm{kg}$ of DM for lactating cow feed, and $\$ 0.18 / \mathrm{kg}$ of
DM for dry cow feed, and the farm received an income of $\$ 0.84 / \mathrm{kg}$ of live weight of replaced animals, $\$ 100$ on average for a calf, and $\$ 0.35 / \mathrm{kg}$ of milk. The milk butterfat was assumed to be $3.5 \%$ and the interest rate was $6 \% / \mathrm{yr}$.

\section{Model Comparison with an Optimization Model}

Results from the present Markov chain model were contrasted with results obtained with a recently published linear programming optimization model (Cabrera, 2010). Within the limitations imposed by the structural and operational differences between the 2 models, every effort was made to replicate the conditions described in Cabrera (2010) with the Markov chain model described in this paper.

\section{RESULTS}

\section{Performance of the Model and Results of Base Scenario at Steady State}

The dynamic calculations of the cow value are portrayed in Figure 1. Figure 1 depicts the NPV of a cow currently in $\mathrm{MIM}=5, \mathrm{MIP}=0$, and $\mathrm{PAR}=2$ $\left(\mathrm{COW}_{5,0,2}\right.$; dashed line) compared with the NPV of its replacement $\left(\mathrm{COW}_{1,0,1}\right.$; continuous line). After including the transaction cost of a replacement (replacement cost - salvage value - calf value), the aggregation of all differences between the 2 curves for 150 iterations (150 mo) or the cow value for $\mathrm{COW}_{5,0,2}$ was $\$ 407$. The 2 lines (dashed and continuous) cross over and fluctuate several times, and their values become closer and closer to each other as the months progress. These curves reflect the sum product of the cow proportions (natural cow population dynamics) in each defined state in the model in every iteration (month) and their expected net returns. The cow being studied as well as the replacement fades over time because proportions of these animals are constantly being replaced. This is the property of the Markov chain model moving toward the steady state. The difference in the discounted values of the cow and a replacement is minimal at 80 mo (last point displayed in Figure 1) and is nonexistent at 150 mo (time at which the cow value was aggregated; not shown). In addition, as time passes, the value for both the cow and its replacement becomes increasingly lower because of the discount imposed.

Overall Results. The model predicted that an average cow had $93 \%$ of its revenue coming from milk sales (Table 2). Feed cost represented $40 \%$ of the milk sales value. Milk income over feed cost was $\$ 6.34 / \mathrm{d}$. The average net return of a cow was $\$ 167 /$ mo. 


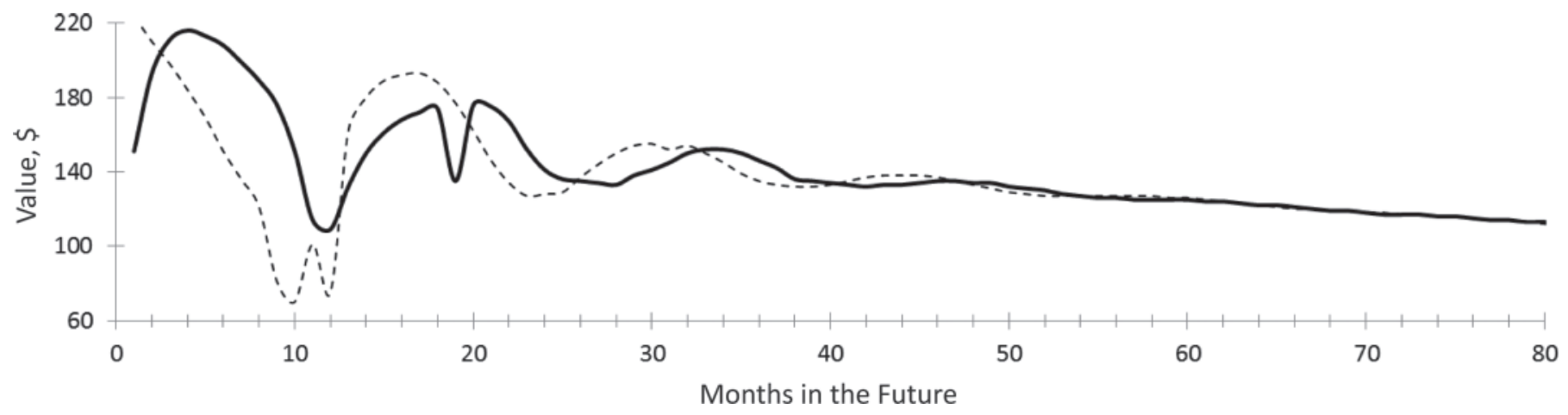

Figure 1. Discounted future value of a replacement cow (solid line) and a nonpregnant cow [month in pregnancy $(\mathrm{MIP})=0$; dashed line] in the second parity $(\mathrm{PAR}=2)$ and fifth month after calving $(\mathrm{MIM}=5)$. The calculated cow value was $\$ 407$.

Comparison with Optimization Model. Selected model outcomes of the present Markov simulation model were not much different from the results found earlier with a linear programming optimization model (Cabrera, 2010). The model developed in the present study predicted only between $\$ 2$ and $\$ 6 /$ cow per month more net return than the previous optimization model, depending on the diet (Table 3 ). In addition, the model presented in the present study predicted only a slightly greater percentage of cows in PAR $=1$ (47 vs. $50 \%$ ) and only a slightly greater percentage of pregnant cows (49 vs. 51\%). The most important decisions to keep or to replace a nonpregnant cow between the 2 models was the same at $\mathrm{MIM}=11$ for PAR $=1$ and only slightly different for PAR $\geq 2$ (Table 3 ).

Cow Value. The cow value for an average nonpregnant cow $(\mathrm{MIP}=0), \mathrm{MIM}=1$, and $\mathrm{PAR}=1$ $\left(\mathrm{COW}_{1,0,1}\right)$ for the base scenario was $\$ 700$. The cow

Table 2. Economic base results for the average cow and herd structure when model reaches steady state

\begin{tabular}{|c|c|}
\hline Parameter & Value \\
\hline \multicolumn{2}{|l|}{ Economic value } \\
\hline Milk sales revenue, $\$ /$ cow per year & 3,834 \\
\hline Feed cost, $\$ /$ cow per year & 1,522 \\
\hline Calf sales revenue, $\$ /$ cow per year & 96 \\
\hline Nonreproductive culling cost, ${ }^{1} \$ /$ cow per year & 197 \\
\hline Mortality cost, ${ }^{2} \$ /$ cow per year & 38 \\
\hline Reproductive culling cost, ${ }^{1} \$ /$ cow per year & 58 \\
\hline Reproductive cost, ${ }^{3} \$ /$ cow per year & 80 \\
\hline \multicolumn{2}{|l|}{ Herd structure } \\
\hline DIM & 224 \\
\hline Days to conception & 122 \\
\hline Pregnant, \% & 52 \\
\hline Reproductive culling, \% & 8 \\
\hline First-parity cows, $\%$ & 43 \\
\hline Second-parity cows, $\%$ & 27 \\
\hline Third-parity cows, $\%$ & 15 \\
\hline$\geq$ Fourth-parity cows, $\%$ & 15 \\
\hline
\end{tabular}

${ }^{1}$ Cost of replacement - cow salvage value - calf value.

${ }^{2}$ Cost of replacement - cow salvage value.

${ }^{3}$ Labor + hormones + AI + pregnancy diagnosis. value increased in PAR $=1$ for $\mathrm{MIM}=2$ to $\$ 717$ and then decreased consistently in successive MIM (Figure 2 ; Table 4). It became negative in MIM $=11$. The cow value for a nonpregnant cow for PAR $=2$ began at its largest value in MIM $=1$ of $\$ 897$ and then decreased consistently in successive MIM, becoming negative at MIM $=9$ (Figure 2). Similar curves were observed in later parities (data not shown). The cow value in MIM $=1$ for $\mathrm{PAR}=3$ to 10 were $\$ 918, \$ 876, \$ 854, \$ 842$, $\$ 838, \$ 831, \$ 816$, and $\$ 780$, respectively.

The cow value of a pregnant cow $($ MIP $>0)$ was always greater than the cow value for a nonpregnant cow at the same PAR and MIM (Figure 2). The cow value of a pregnant cow followed a typical U-shaped curve. It first decreased and then increased. The largest increase occurred between MIP 8 and 9 . The largest values were when MIP $=1$ or 9 . For a pregnancy occurring in MIM $=5$, the largest value occurred in MIP $=9$ and was $\$ 763, \$ 756, \$ 709$, and $\$ 686$ for PAR $=1$ to 4 , respectively. The cow value of a pregnant cow at a defined MIM was greater for cows becoming pregnant earlier, although some exceptions occurred in PAR $=1$. In general, the cow value for a pregnant and a nonpregnant cow increased from PAR $=1$ to $\mathrm{PAR}=3$ (Figure 2; Table 4). It then decreased consistently to PAR $=10$ (data not shown).

The Value of a New Pregnancy. The value of a new pregnancy increased and then decreased with MIM (Figure 3). These values for PAR $=1$ ranged between $\$ 128$ for a cow conceiving in MIM $=3$ and $\$ 232$ for a cow conceiving in MIM $=8$. These values were between $\$ 185$ and $\$ 230$ for PAR $=2$, between $\$ 184$ and $\$ 202$ for $\mathrm{PAR}=3$, and between $\$ 184$ and $\$ 192$ for $\mathrm{PAR}=4$. The peak values were reached in a pregnancy occurring in $\mathrm{MIM}=7$ for PAR $=2$ and in a pregnancy occurring in $\mathrm{MIM}=6$ for $\mathrm{PAR}=3$ and 4 . The increase in the value of a new pregnancy continued for longer MIM for PAR $=1$ because of its more persistent lactation curves. For PAR $=1$, the marginal rate of increase of 
Table 3. Comparison of a previous optimization study (Cabrera, 2010) with the Markov chain simulation model developed in this study

\begin{tabular}{|c|c|c|}
\hline Item & $\begin{array}{l}\text { Linear programming } \\
\text { optimization }^{1}\end{array}$ & $\begin{array}{l}\text { Markov chain model } \\
\text { from this study }\end{array}$ \\
\hline \multicolumn{3}{|c|}{ Net return to defined diets, ${ }^{2} \$ /$ cow per month } \\
\hline Diet 1 & 132 & 138 \\
\hline Diet 2 & 132 & 134 \\
\hline Diet 3 & 117 & 122 \\
\hline Diet 4 & 105 & 109 \\
\hline Diet 5 & 80 & 85 \\
\hline \multicolumn{3}{|c|}{ Herd demographics, ${ }^{3} \%$} \\
\hline $\mathrm{PAR}^{4}=1$ & 47 & 50 \\
\hline $\mathrm{PAR}=2$ & 27 & 27 \\
\hline $\mathrm{PAR} \geq 3$ & 26 & 23 \\
\hline Pregnant cows & 49 & 51 \\
\hline \multicolumn{3}{|c|}{ Replacement decision for a nonpregnant cow, ${ }^{3}$ MIM } \\
\hline $\mathrm{PAR}=1$ & $11^{5}$ & 11 \\
\hline $\mathrm{PAR} \geq 2$ & $10^{5}$ & $9^{6}$ \\
\hline
\end{tabular}

${ }^{1}$ Cabrera (2010).

${ }^{2}$ Diets 1 to 5 contained approximately 50,33, 25, 9, and $0 \%$ of concentrates, respectively (Cabrera, 2010).

${ }^{3}$ The linear programming model optimized the decision to keep or to replace a cow; the Markov chain model used a predefined 10 mo in milk (MIM) after which nonpregnant cows were not bred, and a milk threshold production to remain in the herd of $22.7 \mathrm{~kg} / \mathrm{d}$.

${ }^{4} \mathrm{PAR}=$ parity

${ }^{5}$ One month later for diet 5 .

${ }^{6}$ Ten months after calving for diets 4 and 5.

the value of a new pregnancy was $17 \%$ between MIM = 3 and 4 and $11 \%$ between MIM $=9$ and 10 (data not shown). This rate was lower and of shorter duration for $\mathrm{PAR}=2$ to 4 . In all cases, the decrease in the value of a new pregnancy to zero was precipitous from MIM $=10$ to $\mathrm{MIM}=11$ for $\mathrm{PAR}=1$ and from $\mathrm{MIM}=8$ to MIM $=9$ for PAR $=2$ to 4 (data not shown).

All the economic factors included in the model, except feed costs, contributed positively to the value of a new pregnancy (Table 5). When a new pregnancy occurs, the future expected discounted net return (incomes less costs) increases because of more milk sales, lower culling costs, more calves, and lower reproductive costs. More milk produced and less culling determines higher feed costs. Some exceptions occurred when the pregnancy occurred late in lactation. For a cow becoming pregnant in $\mathrm{MIM}=8$ in $\mathrm{PAR} \geq 3$, the expected milk sales were negative, indicating that lower milk sales were expected from that cow compared with an identical nonpregnant cow (Table 5).
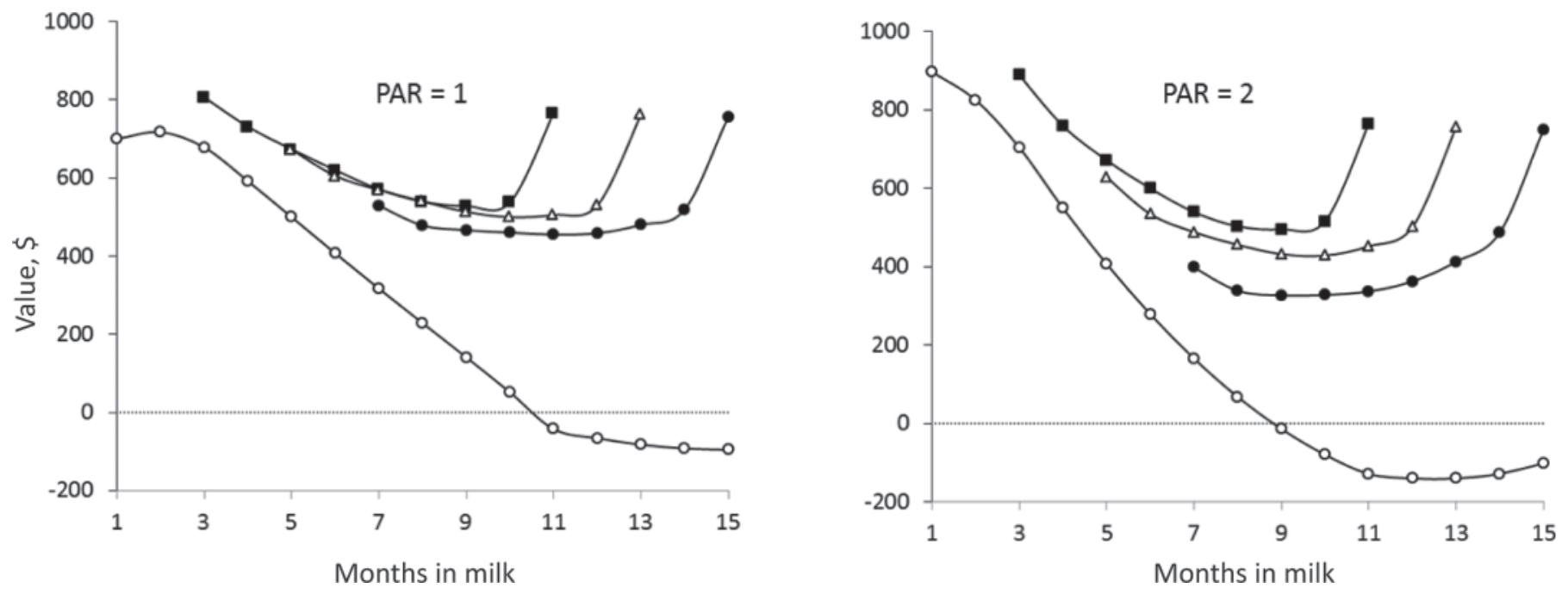

Figure 2. Cow value for a cow that became pregnant at month in milk (MIM) $=3$ (solid squares), MIM $=5$ (open triangles), and MIM $=$ 7 (solid circles), and cow value for a nonpregnant cow (open circles) for parities (PAR) 1 and 2 . 
Table 4. Cow value at average milk production (100\%) and percentage (\%) of milk production for the cow value to break even according to parity (PAR), month in milk (MIM), and month in pregnancy (MIP)

\begin{tabular}{|c|c|c|c|c|c|c|c|c|c|c|}
\hline \multirow[b]{2}{*}{ MIM } & \multirow[b]{2}{*}{ MIP } & \multicolumn{3}{|c|}{$\mathrm{PAR}=1$} & \multicolumn{3}{|c|}{$\mathrm{PAR}=2$} & \multicolumn{3}{|c|}{$\mathrm{PAR}=3$} \\
\hline & & $\begin{array}{c}\text { Cow } \\
\text { value, } \\
\$\end{array}$ & $\begin{array}{l}\% \text { of milk } \\
\text { in rest of } \\
\text { lactation }\end{array}$ & $\begin{array}{c}\% \text { of milk } \\
\text { in successive } \\
\text { lactations }\end{array}$ & $\begin{array}{c}\text { Cow } \\
\text { value, } \\
\$\end{array}$ & $\begin{array}{l}\% \text { of milk } \\
\text { in rest of } \\
\text { lactation }\end{array}$ & $\begin{array}{l}\% \text { of milk in } \\
\text { successive } \\
\text { lactations }\end{array}$ & $\begin{array}{c}\text { Cow } \\
\text { value, } \\
\$\end{array}$ & $\begin{array}{l}\% \text { of milk } \\
\text { in rest of } \\
\text { lactation }\end{array}$ & $\begin{array}{c}\% \text { of milk in } \\
\text { successive } \\
\text { lactations }\end{array}$ \\
\hline 1 & 0 & 700 & 86 & 86 & 897 & 84 & 78 & 918 & 83 & 74 \\
\hline 2 & 0 & 717 & 86 & 86 & 825 & 84 & 80 & 858 & 83 & 77 \\
\hline 3 & 0 & 678 & 86 & 88 & 704 & 85 & 84 & 733 & 84 & 81 \\
\hline 4 & 1 & 743 & 80 & 90 & 756 & 80 & 88 & 768 & 80 & 87 \\
\hline 4 & 2 & 731 & 78 & 90 & 759 & 78 & 89 & 770 & 78 & 87 \\
\hline 5 & 0 & 500 & 89 & 90 & 407 & 90 & 90 & 413 & 90 & 88 \\
\hline 5 & 1 & 673 & 81 & 91 & 628 & 83 & 90 & 625 & 83 & 89 \\
\hline 5 & 3 & 674 & 74 & 92 & 672 & 76 & 91 & 665 & 76 & 90 \\
\hline 6 & 0 & 407 & 90 & 91 & 279 & 93 & 92 & 277 & 92 & 92 \\
\hline 6 & 1 & 601 & 82 & 92 & 509 & 85 & 92 & 492 & 85 & 92 \\
\hline 8 & 1 & 461 & 85 & 93 & 298 & 90 & 95 & 263 & 91 & 95 \\
\hline 8 & 6 & 540 & 43 & 94 & 503 & 50 & 94 & 461 & 55 & 94 \\
\hline 9 & 0 & 141 & 96 & 95 & -14 & 101 & 101 & -17 & 101 & 101 \\
\hline 9 & 1 & 398 & 87 & 94 & 207 & 92 & 96 & 167 & 94 & 97 \\
\hline 9 & 6 & 520 & 44 & 94 & 465 & 52 & 94 & 417 & 57 & 95 \\
\hline 10 & 0 & 51 & 98 & 98 & -80 & 103 & 107 & -73 & 104 & 105 \\
\hline 10 & 1 & 342 & 88 & 95 & 129 & 95 & 97 & 84 & 97 & 98 \\
\hline 10 & 6 & 500 & 45 & 94 & 429 & 54 & 95 & 377 & 59 & 95 \\
\hline 11 & 0 & -43 & 102 & 103 & -129 & 107 & 114 & -105 & 107 & 137 \\
\hline 11 & 1 & 290 & 89 & 95 & 59 & 98 & 99 & 10 & 100 & 100 \\
\hline 11 & 6 & 479 & 46 & 95 & 394 & 56 & 95 & 340 & 61 & 96 \\
\hline 12 & 0 & -66 & 103 & 103 & -141 & 109 & 113 & -115 & 109 & 134 \\
\hline 12 & 1 & 239 & 91 & 96 & -5 & 100 & 100 & -59 & 103 & 101 \\
\hline
\end{tabular}

${ }^{1}$ Milk production of the cow (\% of the average cow) from the current state to the end of the present lactation.

${ }^{2}$ Milk production of the cow (\% of the average cow) in all successive lactations.

The Cost of Pregnancy Loss. The cost of a pregnancy loss increased consistently with MIP. The lowest value was when the MIP $=1$, and the largest value was when the MIP $=9$ (Figure 4 ). For PAR $=1$, it was always greater when the MIM at which the pregnancy occurred was higher. For later PAR, it was not consistent. At MIP $\geq 4$, the curves crossed. This indicated that the pregnancy loss value decreased at higher MIM at the same MIP (Figure 4). It varied between $\$ 128$ for a pregnancy loss in PAR $=1, \mathrm{MIM}=3$, and $\mathrm{MIP}=1$ to $\$ 897$ for a pregnancy loss for $\mathrm{PAR}=2, \mathrm{MIM}=13$, and MIP $=9$. Inside a PAR, it ranged between $\$ 128$ and $\$ 852, \$ 185$ and $\$ 897, \$ 184$ and $\$ 821$, and $\$ 184$ and $\$ 797$ for PAR $=1$ to 4 , respectively (Figure 4 ). The value of a pregnancy loss equals the value of a new pregnancy when the pregnancy loss occurs in MIP = 1. Because the cost of a pregnancy loss increased with MIP, overall, the cost of a pregnancy loss was greater than the value of a new pregnancy.

The cost of a pregnancy loss is explained by lower milk sales, higher culling costs, lower calf revenues, and higher reproduction costs (Table 5). As in the case of a new pregnancy, the feed costs were greater for the pregnant cow than for the nonpregnant cow. The greater cost of pregnancy loss in late pregnancy $(\mathrm{MIP}=9)$ was mostly due to losses in milk sales and reproductive culling costs. The reproductive culling cost is about 3 times greater in $\mathrm{PAR}=1$ than in $\mathrm{PAR} \geq 2$. The milk sales 
expected for a pregnant cow became negative in PAR $=$ $5, \mathrm{MIM}=11$, and $\mathrm{MIP}=6$, indicating that more milk sales were expected from an identical nonpregnant cow.

\section{Assessment of Expected Milk Production of a Cow}

The cow value was positively and largely related to the expected milk production in both nonpregnant (Figure 5) and pregnant cows (Table 6). The economic effect on the cow value for nonpregnant cows expecting a differential in milk production in the current lactation or in successive lactations was not much different (Figure 5). When the expected milk production was $120 \%$, the cow value was between 2 and 2.5 times greater than the cow value with average milk production in early MIM, and the cow value was between 8 and 10 greater than the cow value with average milk production in late MIM. When the expected milk production was $80 \%$, these values were between $-\$ 700$ and $-\$ 1,127$ in early MIM and between $-\$ 236$ and $-\$ 631$ in later MIM, lower than the cow value for the average cow. When the expected milk production was $80 \%$ for successive lactations, the cow value was positive only for MIM = $1, \mathrm{PAR}=2$ or for $\mathrm{MIM}=1$ and $2, \mathrm{PAR}=3$ (Figure 5$)$.

The impact of the expected milk production on the cow value of pregnant cows was different for milk production in this lactation and milk production in successive lactations (Table 6). The impact was greater for the

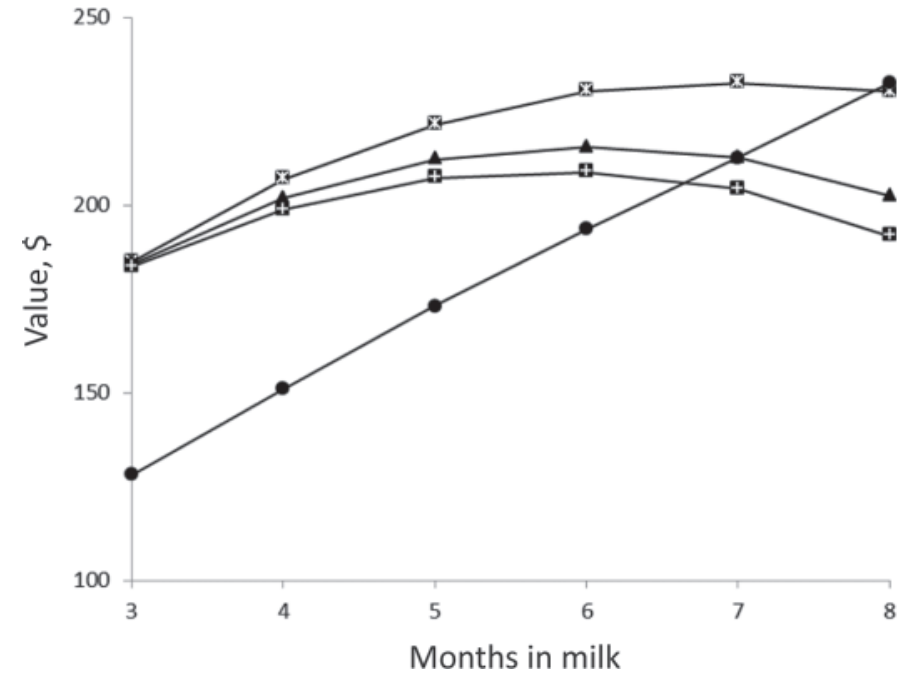

Figure 3. Value of a new pregnancy by month in milk (MIM) and parity [PAR; 1 (solid circles); 2 (solid squares with an asterisk); 3 (solid triangles); 4 (solid squares with a plus)]. Value was zero for MIM $\geq 11$ for $\mathrm{PAR}=1$ and for $\mathrm{MIM} \geq 9$ for $\mathrm{PAR}=2$ to 4 .

expected milk production in successive lactations than the expected milk production in the rest of the present lactation. This difference enlarged as the gestation progressed. For a cow in MIM $=4$ and $\mathrm{MIP}=1$, a $120 \%$ expected milk production in the rest of this lactation would have about 2 times greater cow value, whereas a $120 \%$ expected milk production in successive lactations

Table 5. Value of a new pregnancy and the cost of a pregnancy loss explained by the difference in sums of discounted future incomes and costs when comparing a pregnant cow with an identical nonpregnant cow

\begin{tabular}{|c|c|c|c|c|c|c|c|c|c|c|}
\hline & & & \multicolumn{8}{|c|}{$\begin{array}{l}\text { Difference in sums of discounted future incomes and costs } \\
\text { between a pregnant and a nonpregnant cow, } \$\end{array}$} \\
\hline & & & & & & \multicolumn{3}{|c|}{ Culling } & \multirow[b]{2}{*}{ Calf } & \multirow[b]{2}{*}{ Reproduction } \\
\hline \multicolumn{3}{|c|}{ State of pregnant cow ${ }^{1}$} & Cow value & Milk & Feed & Reproductive & Nonreproductive & Mortality & & \\
\hline PAR & MIM & MIP & \multicolumn{8}{|c|}{ - Value of a new pregnancy } \\
\hline 1 & 4 & 1 & 151 & 36 & -34 & 45 & 26 & 5 & 29 & 45 \\
\hline 1 & 6 & 1 & 194 & 40 & -40 & 73 & 39 & 8 & 32 & 41 \\
\hline 1 & 8 & 1 & 233 & 22 & -43 & 116 & 55 & 10 & 36 & 36 \\
\hline 3 & 4 & 1 & 202 & 46 & -17 & 43 & 46 & 9 & 26 & 49 \\
\hline 3 & 6 & 1 & 215 & 39 & -25 & 69 & 50 & 9 & 27 & 47 \\
\hline 3 & 8 & 1 & 203 & -9 & -29 & 108 & 53 & 10 & 27 & 43 \\
\hline 5 & 4 & 1 & 196 & 36 & -17 & 37 & 55 & 10 & 26 & 49 \\
\hline 5 & 6 & 1 & 203 & 25 & -22 & 60 & 57 & 11 & 26 & 47 \\
\hline 5 & 8 & 1 & 186 & -24 & -25 & 94 & 61 & 12 & 26 & 44 \\
\hline 1 & 8 & 3 & 610 & 54 & -91 & 421 & 125 & 24 & 71 & 8 \\
\hline 1 & 11 & 6 & 572 & 52 & -117 & 437 & 96 & 18 & 97 & -12 \\
\hline 1 & 14 & 9 & 852 & 482 & -221 & 428 & 65 & 12 & 117 & -32 \\
\hline 3 & 8 & 3 & 305 & 59 & -39 & 140 & 55 & 11 & 46 & 33 \\
\hline 3 & 11 & 6 & 279 & 8 & -17 & 157 & 36 & 7 & 72 & 16 \\
\hline 3 & 14 & 9 & 645 & 463 & -93 & 150 & 27 & 5 & 97 & -4 \\
\hline 5 & 8 & 3 & 280 & 37 & -33 & 124 & 63 & 12 & 44 & 33 \\
\hline 5 & 11 & 6 & 252 & -21 & -10 & 138 & 48 & 9 & 71 & 17 \\
\hline 5 & 14 & 9 & 622 & 431 & -87 & 132 & 43 & 8 & 96 & -2 \\
\hline
\end{tabular}

${ }^{1} \mathrm{PAR}=$ parity; MIM = month after calving or month in milk; MIP = month in pregnancy. 
would have about 2.75 times greater cow value than the average cow (Table 6). For a cow in MIM $=16$ and MIP $=6$, a $120 \%$ expected milk production in the remainder of this lactation would have only about 1.52 times greater cow value, whereas a $120 \%$ expected milk production in successive lactations would have about 6.48 greater cow value than the average cow (Table 6). The cow value of a pregnant cow was negative for MIM $=4$ and MIP $=1$ only when expected milk production in successive lactations was $80 \%$ and the expected milk production for the rest of this lactation was average or $80 \%$ of production of the average herd cow. In addition, for $\mathrm{MIM}=16$ and MIP $=6$, the cow value was negative only when the expected milk production in successive lactations was $80 \%$. This occurred even when the expected milk production in the rest of this lactation was $120 \%$ that of the average cow.

\section{Assessment of Genetic Improvement of Replacement Heifers}

Genetic improvement had a linear and negative relationship with the estimated cow value. Under all other base values of Table 1, the cow value decreased by $\$ 211$ for every 1 percentage point increase in the expected genetic gain of the replacements. Because genetic improvement affects only the replacement animals, no interaction was observed between genetic improvement and other factors specific to the cow being analyzed, such as expected milk production for the rest of the lactation or expected milk production for successive lactations.

\section{Breakeven Analysis}

Expected milk production for the rest of the current lactation for the cow value to break even was always $<100 \%$ for cows becoming pregnant in MIM $<10$, and it was much lower for cows in later pregnancy (Table 4). An interaction was observed between the MIP and the MIM in which the cow became pregnant. The later the pregnancy, the higher the milk production required in the current lactation for the cow value to break even. For PAR $=1$, the break-even value of a pregnant cow with respect to the current lactation milk production was always $<100 \%$. More than $100 \%$ milk production in the current lactation was required for the cow value of pregnant cows to break even when the pregnancy occurred in MIM $>12$ for PAR $=2$ and in MIM $>11$ for PAR $>2$. For nonpregnant cows, a break-even cow value was achieved when the milk in the rest of the lactation was $<100 \%$ for MIM $\leq 10$ and PAR $=1$ and for $\mathrm{MIM} \leq 8$ and PAR $\geq 2$. In all other cases, nonpreg- nant cows needed $>100 \%$ milk production in the rest of lactation to reach a break-even cow value (Table 4).

Expected milk production in successive lactations for the cow value to break even was not much different from the expected milk production in the current lactation for the cow value for nonpregnant cows (MIP = $0)$ or newly pregnant cows $(\mathrm{MIP}=1)$ to break even (Table 4 ). For MIP $=0$ and MIP $=1$, the expected milk production for the current and successive lactations for the cow value to break even followed the same pattern (Table 4). However, the expected milk production in the current lactation for the cow value to break even became much lower than the expected milk production in successive lactations for the cow value to break even when the cow was later in pregnancy (MIP $\geq 2$ ).

\section{DISCUSSION}

The model framework and its associated decision support system provide the opportunity to make permanent cow value calculations and, more important, to combine those calculations with the intuitive rationale of the farmer to make more appropriate decisions. Usually, farmers would use this intuitive process anyway to directly judge either to keep or to replace a cow. Using this intuitive process within a robust model is a large improvement and something that has not been integrated within the traditional DP approach in the past. A great advantage and strength of the model framework presented here is that it is less complex and more suitable for a decision support system, which makes it more likely to be used in practical decision making by farmers and consultants. It was implemented as a simple spreadsheet matrix and as an online system, and it is instantly solved when parameters are manipulated. These facts certainly promote and support a more interactive and dynamic decision-making process (Groenendaal et al., 2004). Using a Markov chain framework allowed this comprehensive model to be contained in a simple spreadsheet without the need for any code programming or an online application, making the application highly interactive, dynamic, user friendly, and robust.

Consistent with previous reports (de Vries, 2006; Kalantari et al., 2010; Nielsen et al., 2010), the cow value of an average nonpregnant cow 1) decreased later in lactation, 2) became negative sometime after 250 DIM, 3) was positive for a longer time for first-parity cows, and 4) increased from first to third parity and then decreased for later parities. Also consistent with previous research (de Vries, 2006), the cow value of an average pregnant cow 1) was greater than that of a similar nonpregnant cow, 2) followed a U-shaped curve during gestation, 3) decreased from an early to late 

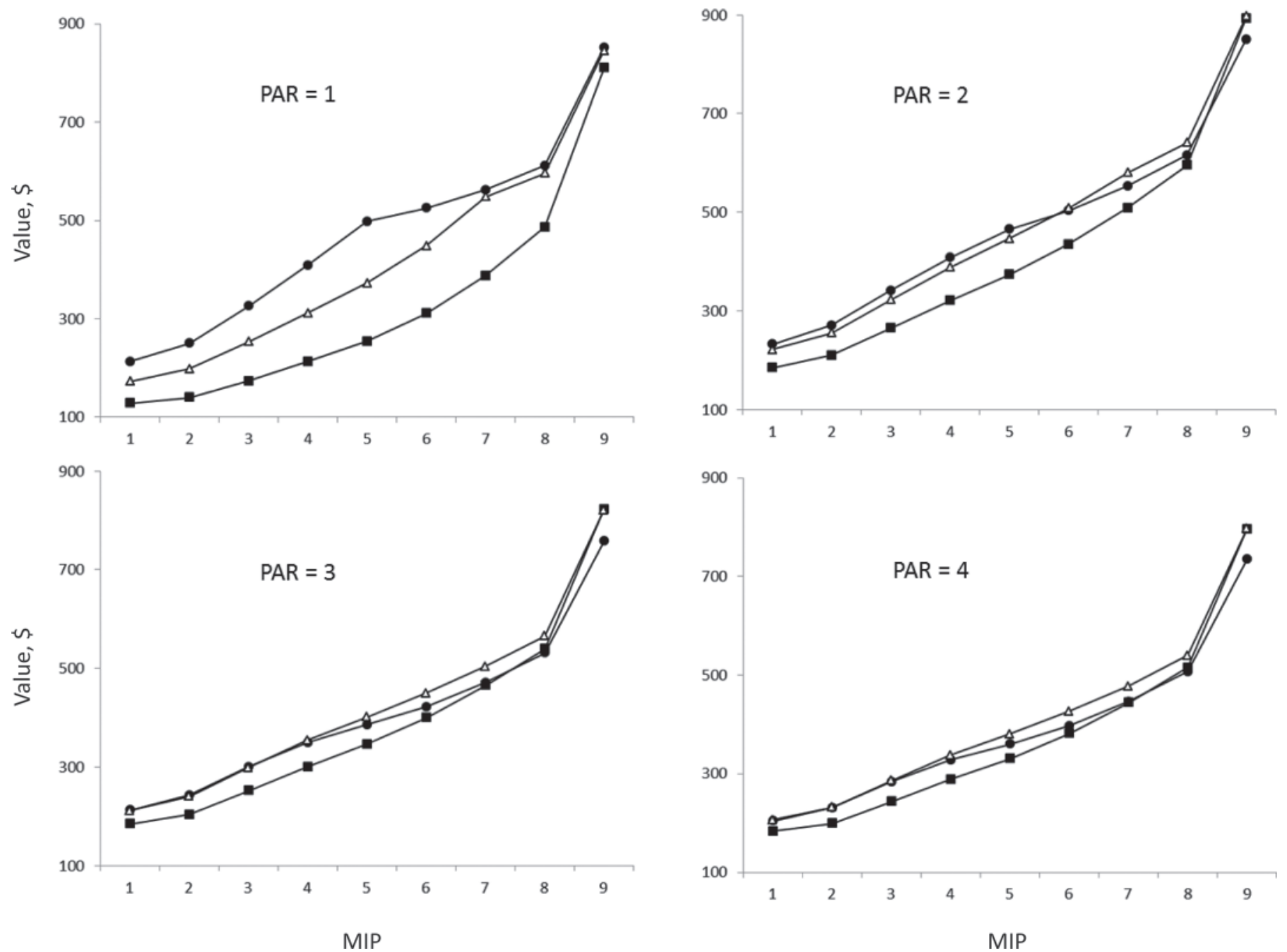

Figure 4. Cost of a pregnancy loss for a cow that became pregnant at month in milk (MIM) $=3$ (solid squares), MIM $=5$ (open triangles), and $\mathrm{MIM}=7$ (solid circles) for month in pregnancy (MIP) 1 to 9 and parities (PAR) 1 to 4 .

time of pregnancy, and 4) increased from the first to third parity and then decreased for later parities.

Only small differences were found when comparing the present Markov chain model with a previous optimization model (Cabrera, 2010). Judging by these similitudes (Table 3 ), the present model could be considered as robust as the previous one to estimate the net return and the herd demographics and, more important, to make replacement decisions. These comparisons seem to indicate that, under a reasonable set of reproductive replacement criteria, the model presented here will allow decision makers to have close to optimal decisions. Over time, these decisions would lead to optimal herd performance.

Differences when comparing the absolute values found in the present study with those in other studies (de Vries, 2006; Kalantari et al., 2010; Nielsen et al., 2010) could be attributable to differences in the input parameters and in the transition probabilities. Another source of differences was the preexisting reproductive culling policy implemented in the present study. The model presented here does not assume an optimal reproductive culling policy in the future of a cow, as is done in DP, but rather the predefined policy of a farmer. Arguably, a nonoptimal, farmer-predefined reproductive culling policy assumption could be considered more realistic than always assuming an optimal reproductive culling policy for the future life of a cow and its replacements. Whether formally established or intuitively, dairy farmers and managers have in place a policy to cull cows that are not becoming pregnant. Moreover, this policy would constantly change, depending on factors directly affecting the dairy farm enterprise, such as market conditions, farm goals, or herd performance, or indirect factors, such as the family goals of the farmer. Therefore, allowing the farmer to 


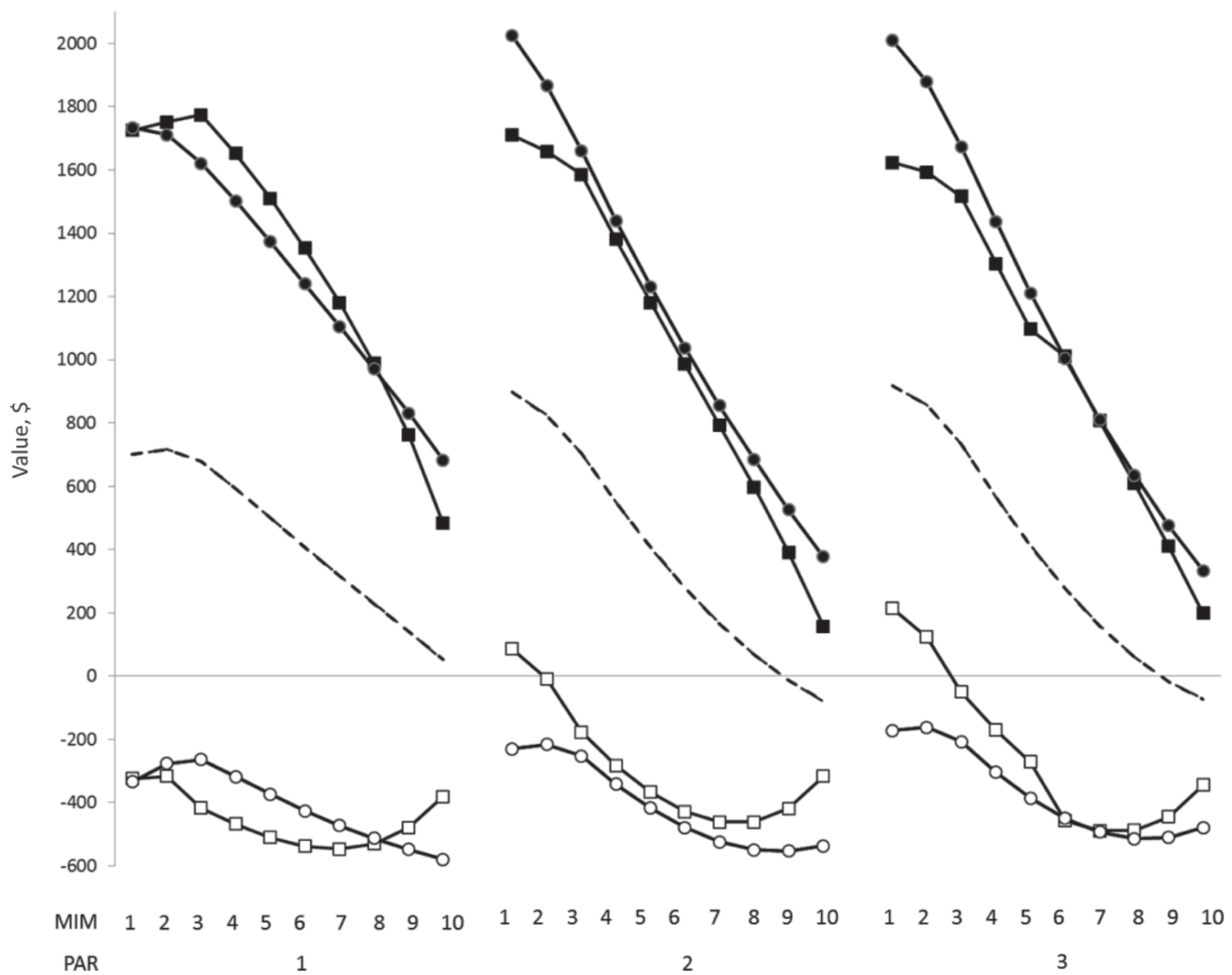

Figure 5. The cow value of a nonpregnant cow by parity (PAR) and month after calving or month in milk (MIM) when the expected milk production for the present lactation is $120 \%$ (solid circles) or $80 \%$ (open circles) of the average cow and when the expected milk production for successive lactations is $120 \%$ (solid squares) or $80 \%$ (open squares) of the average cow. The dashed curves represent the cow value at average milk production $(100 \%)$.

define and adjust reproductive culling policies could be advantageous from the farmer's decision-making point of view. Still, a farmer could achieve a culling policy closer to optimal by engaging in an interactive process of applying the decision support tool presented here.

Continuing the discussion of the preexisting culling policy, the possibility of labeling a cow as "do not breed" is certainly an advance in the decision making of the replacement problem, which definitely makes a difference in the cow value calculation (Figure 2). Consistent with the method of Eicker and Fetrow (2003), labeling a cow as "do not breed" increases its cow value because no more services are performed on the cow and its replacement is imminent after the milk production goes below a defined minimum threshold. A further analysis, beyond the scope of the present study, that could be carried out with the model presented here would be to explore best reproductive culling policies in terms of the optimal time to select cows as "do not breed" and a milk threshold to cull a nonpregnant cow in light of other important parameters, such as milk production expectancy and the possible genetic gain of replacements.

The model and decision support system presented here use a farmer's estimation of defined milk expectancy in the future with respect to an average-producing cow (during the rest of the current lactation and during successive lactations) and a genetic gain 
Table 6. Effect of expected milk production on the cow value of pregnant cows ${ }^{1}$

\begin{tabular}{|c|c|c|c|c|c|c|}
\hline \multirow[b]{2}{*}{ MIM } & \multirow[b]{2}{*}{ MIP } & \multicolumn{2}{|c|}{ Expected milk production } & \multicolumn{3}{|c|}{ Cow value, $\$$} \\
\hline & & $\begin{array}{l}\text { Rest of } \\
\text { lactation }^{2}\end{array}$ & $\begin{array}{l}\text { Successive } \\
\text { lactations }^{3}\end{array}$ & $\mathrm{PAR}=1$ & $\mathrm{PAR}=2$ & $\mathrm{PAR}=3$ \\
\hline \multirow[t]{9}{*}{4} & 1 & 120 & 120 & 2,967 & 2,800 & 2,703 \\
\hline & & 120 & 100 & 1,468 & 1,516 & 1,533 \\
\hline & & 120 & 80 & -30 & 232 & 363 \\
\hline & & 100 & 120 & 2,242 & 2,040 & 1,938 \\
\hline & & $100^{1}$ & $100^{1}$ & $743^{1}$ & $756^{1}$ & $768^{1}$ \\
\hline & & 100 & 80 & -756 & -529 & -402 \\
\hline & & 80 & 120 & 1,516 & 1,280 & 1,173 \\
\hline & & 80 & 100 & 18 & -5 & 3 \\
\hline & & 80 & 80 & $-1,481$ & $-1,289$ & $-1,167$ \\
\hline \multirow[t]{9}{*}{8} & 2 & 120 & 120 & 2,458 & 2,038 & 2,002 \\
\hline & & 120 & 100 & 1,045 & 877 & 829 \\
\hline & & 120 & 80 & -380 & -284 & -345 \\
\hline & & 100 & 120 & 1,891 & 1,499 & 1,477 \\
\hline & & $100^{1}$ & $100^{1}$ & $479^{1}$ & $338^{1}$ & $304^{1}$ \\
\hline & & 100 & 80 & -934 & -823 & -870 \\
\hline & & 80 & 120 & 1,325 & 961 & 952 \\
\hline & & 80 & 100 & -88 & -200 & -221 \\
\hline & & 80 & 80 & $-1,501$ & $-1,361$ & $-1,395$ \\
\hline \multirow[t]{9}{*}{12} & 4 & 120 & 120 & 2,307 & 1,842 & 1,797 \\
\hline & & 120 & 100 & 719 & 529 & 461 \\
\hline & & 120 & 80 & -869 & -784 & -875 \\
\hline & & 100 & 120 & 1,977 & 1,535 & 1,501 \\
\hline & & $100^{1}$ & $100^{1}$ & $389^{1}$ & $223^{1}$ & $165^{1}$ \\
\hline & & 100 & 80 & $-1,198$ & $-1,090$ & $-1,171$ \\
\hline & & 80 & 120 & 1,648 & 1,229 & 1,205 \\
\hline & & 80 & 100 & 60 & -84 & -131 \\
\hline & & 80 & 80 & $-1,528$ & 1,396 & $-1,467$ \\
\hline \multirow[t]{9}{*}{16} & 6 & 120 & 120 & 2,220 & 1,864 & 1,859 \\
\hline & & 120 & 100 & 535 & 409 & 348 \\
\hline & & 120 & 80 & $-1,149$ & $-1,047$ & $-1,162$ \\
\hline & & 100 & 120 & 2,065 & 1,718 & 1,717 \\
\hline & & $100^{1}$ & $100^{1}$ & $380^{1}$ & $262^{1}$ & $207^{1}$ \\
\hline & & 100 & 80 & $-1,304$ & $-1,193$ & $-1,304$ \\
\hline & & 80 & 120 & 1,910 & 1,572 & 1,575 \\
\hline & & 80 & 100 & 225 & 116 & 65 \\
\hline & & 80 & 80 & $-1,459$ & $-1,340$ & $-1,446$ \\
\hline
\end{tabular}

${ }^{1}$ Values represent the cow in the herd with average production. MIM = month after calving or month in milk; $\mathrm{MIP}=$ month in pregnancy; $\mathrm{PAR}=$ parity.

${ }^{2}$ Cow's expected milk production ( $\%$ of the average cow) from the current state to the end of the present lactation.

${ }^{3}$ Cow's expected milk production (\% of the average cow) in all successive lactations.

of the replacement, measured as additional milk produced by the replacement animal with respect to an average cow. These were believed to be appropriated from the decision-making perspective of the producer. Nonetheless, it should be recognized that cows and replacements would not have only a unidirectional milk production change with respect to the average cow in the future, but would probably have combined directions, depending on probabilistic distributions according to milk classes, as has been implemented within the DP approach (de Vries, 2006; Kalantari et al., 2010). Such a concept of milk classes could be implemented within the framework presented here and could be a serious consideration for future research. Even if using milk classes, no major differences in the calculated cow values would be expected, judging by the differences between results presented here and previous reports. The user-defined milk expectancy was believed to be adequate, relevant, and advantageous for the main purpose of the present study of achieving a simple, userfriendly decision support system.

\section{CONCLUSIONS}

The present study demonstrated that a formulation of the dairy cow replacement problem using a simple 
Markov chain approach was valid and that it replicated overall policy decisions previously reported with more complex models. This formulation was able to handle differential expected milk production of the cow being analyzed and genetic gain of the replacement. The model developed in this study contributes to the research literature by providing a new formulation for the cow replacement problem, and its associated user-friendly decision support system contributes to the Extension deliverables by providing a tool that would more likely be adopted and applied for practical decision making. The replacement policy called for replacing nonpregnant cows 11 mo after calving in the first lactation and 9 mo after calving in later lactations. The cow value indicated that pregnant cows should be kept, except in some situations when the cow became pregnant after the nonpregnant value had become negative. The expected future production of a cow was an important determinant in the cow replacement decision. The expected production in the rest of the lactation was more important for nonpregnant cows, and the expected production in successive lactations was more important for pregnant cows. The cow value decreased by $\$ 211$ for every 1 percentage point of expected genetic gain of the replacement. The model was suitable for building a highly user-friendly decision support system. The decision support system is contained as a simple spreadsheet and as an online application. This tool is capable of calculating the cow value instantaneously, interactively, and dynamically. Because of its simplicity, this decision support system is more likely to be adopted and applied for practical decision making on commercial dairy farms. The decision support system tool is openly and freely available at http://dairymgt. info/ $\rightarrow$ Tools $\rightarrow$ The Economic Value of a Dairy Cow.

\section{ACKNOWLEDGMENTS}

This project was supported by Agriculture and Food Research Initiative Competitive Grant No. 2010-8512220612 from the USDA National Institute of Food and Agriculture (Washington, DC). This research was also supported by Hatch Project No. WIS01577 to V.E.C. Thanks are extended to L. Armentano and A. Kalantari (Department of Dairy Science, University of Wisconsin), and two anonymous reviewers for providing comments to improve the clarity of this manuscript.

\section{REFERENCES}

Bell, M. J., E. Wall, G. Russell, G. Simm, and A. W. Stott. 2011. The effect of improving cow productivity, fertility, and longevity on the global warming potential of dairy systems. J. Dairy Sci. 94:3662-3678.

Bellman, R. 1957. Dynamic Programming. Princeton University Press, Princeton, NJ.

Cabrera, V. E. 2010. A large Markovian linear program to optimize replacement policies and dairy herd net income for diets and nitrogen excretion. J. Dairy Sci. 93:394-406.

Cabrera, V. E., A. de Vries, and P. E. Hildebrand. 2006. Prediction of nitrogen excretion in dairy farms located in North Florida: A comparison of three models. J. Dairy Sci. 89:1830-1841.

Cabrera, V. E., and J. O. Giordano. 2010. Economic decision making for reproduction. Pages 77-86 in Proc. Dairy Cattle Reproduction Council Convention, St. Paul, MN.

Cabrera, V. E., C. P. Mathis, R. E. Kirksey, and T. T. Baker. 2008. Development of a seasonal prediction model for manure excretion by dairy cattle. Prof. Anim. Sci. 24:175-183.

de Vries, A. 2004. Economics of delayed replacement when cow performance is seasonal. J. Dairy Sci. 87:2947-2958.

de Vries, A. 2006. Economic value of pregnancy in dairy cattle. J. Dairy Sci. 89:3876-3885.

de Vries, A., J. D. Olson, and P. J. Pinedo. 2010. Reproductive risk factors for culling and productive life in large dairy herds in the eastern United States between 2001 and 2006. J. Dairy Sci. 93:613-623.

Demeter, R. M., A. R. Kristensen, A. G. Dijkstra, A. G. J. M. Oude Lansink, M. P. M. Meuwissen, and J. A. M. van Arendonk. 2011. A multi-level hierarchic Markov process with Bayesian updating for herd optimization and simulation in dairy cattle. J. Dairy Sci. 94:5938-5962.

Ehrlich, J. L. 2011. Quantifying shape of lactation curves, and benchmark curves for common dairy breeds and parities. Bovine Pract. 45:88-95.

Eicker, S., and J. Fetrow. 2003. New tools for deciding when to replace used dairy cows. Pages 33-46 in Proc. 2003 Kentucky Dairy Conf., Cave City, KY. Univ. Kentucky, Lexington.

Groenendaal, H., D. Galligan, and H. Mulder. 2004. An economic spreadsheet model to determine optimal breeding and replacement decisions for dairy cattle. J. Dairy Sci. 87:2146-2157.

Heikkilä, A.-M., J. I. Nousiainen, and L. Jauhiainen. 2008. Optimal replacement policy and economic value of dairy cows with diverse health status and production capacity. J. Dairy Sci. 91:2342-2352.

Hillier, F. S., and G. J. Lieberman. 1986. Introduction to Operations Research. 4th ed. Holden-Day, San Francisco, CA.

Kalantari, A. S., H. Mehrabani-Yeganeh, M. Moradi, A. H. Sanders, and A. De Vries. 2010. Determining the optimum replacement policy for Holstein dairy herds in Iran. J. Dairy Sci. 93:2262-2270.

Korver, S., J. A. M. van Arendonk, and W. J. Koops. 1985. A function for live-weight change between two calvings in dairy cattle. Anim. Prod. 40:233-241.

Kristensen, A. R. 1987. Optimal replacement and ranking of dairycows determined by a hierarchical Markov process. Livest. Prod. Sci. 16:131-144.

Nielsen, L. R., E. Jorgensen, A. R. Kristensen, and S. Ostergaard 2010. Optimal replacement policies for dairy cows based on daily yield measurements. J. Dairy Sci. 93:75-92.

NRC. 2001. Nutrient Requirements of Dairy Cattle. 7th rev. ed. Natl. Acad. Press, Washington, DC.

Smith, R. M., J. F. Taylor, J. P. Walter, M. A. Tomaszewski, C. G. Woelfel, and D. J. Leatham. 1993. Seasonal effects on income over feed and replacement costs. J. Dairy Sci. 76:1678-1692.

St-Pierre, N. R., and L. R. Jones. 2001. Forecasting herd structure and milk production for production risk management. J. Dairy Sci. 84:1805-1813.

VandeHaar, M., H. Bucholtz, R. Beverly, R. Emery, M. Allen, C. Sniffen, and R. Black. 1992. Spartan dairy ration evaluator/balancer. An agricultural integrated management software microcomputer program. CP-012 Version 2.01. Cooperative Extension Service and Agricultural Experiment Station, Michigan State Univ., East Lansing. 